\title{
Entrevista
}

\section{Entrevista de Emanuela Cresti e Massimo Moneglia}

\author{
por Tommaso Raso* e Maryualê M. Mittmann ${ }^{* *}$
}

Emanuela Cresti e Massimo Moneglia dirigem o Laboratório de Italianística da Universidade de Florença - LABLITA - na Itália (http://lablita.dit.unifi.it/). Ambos têm trabalhado há muitas décadas sobre a fala espontânea, através da produção de corpora multilíngues de fala espontânea (o mais famoso dos quais é o C-ORAL-ROM, que apresenta corpora comparáveis de italiano, francês, português europeu e espanhol), a partir dos quais elaboraram uma teoria de análise da fala de base pragmática, que, explorando a noção austiniana de ato de fala, identifica na ilocução o núcleo do enunciado e em diversas unidades informacionais, as unidades opcionais que podem contribuir para a construção do mesmo ${ }^{1}$.

Esta entrevista foi realizada em duas diferentes conversas via Skype no mês de outubro 2013. As perguntas de partida para a discussão foram cinco, gerando assim cinco núcleos de discussão: a primeira parte da entrevista visa a enfrentar as diferenças de fundo entre a linguagem veiculada pela fala e pela escrita; a segunda tenta investigar o porquê de a tradição linguística ter tido dificuldades em perceber essas diferenças; a terceira se concentra nos méritos e nos limites da tradição lógico-formal na análise da linguagem, com particular atenção ao estudo do conceito de ilocução; a quarta, e última parte da entrevista, concentra-se no diferente papel da sintaxe na fala e na escrita.

\footnotetext{
${ }^{*}$ T. Raso é prof. Titular em Linguística na UFMG. Foi professor associado na UCLA e professor associado na Università di Venezia. Coordena o projeto C-ORAL-BRASIL dentro um acordo institucional com a Università di Firenze.

${ }^{* *}$ M. Mittmann é doutora em Linguística (UFMG). Tem trabalhado no projeto C-ORAL-BRASIL, e realizou estágio de alguns meses no laboratório LABLITA da Università di Firenze.

${ }^{1}$ A essa altura, a bibliografia sobre a Teoria da Língua em Ato é ampla. A primeira formalização geral é o livro de E. Cresti Corpus dell'italiano parlato, publicado em 2000 pela Accademia della Crusca. Entre as principais contribuições posteriores, citamos os textos de Cresti e de Moneglia em C-ORAL-ROM: Integrated reference corpora for spoken Romance languages. Amsterdam: John Benjamins, 2005. O corpus C-ORAL-BRASIL, de Raso e Mello, publicado pela Editora da UFMG em 2012, inclui o português do Brasil na mesma família de corpora comparáveis e oferece uma versão da teoria em português. Nos sites do LABLITA e do C-ORAL-BRASIL (www.c-oral-brasil.org) é possível baixar diversos outros trabalhos, em italiano, inglês e português.
} 
Ao longo da entrevista, diferenciamos as intervenções dos entrevistadores (abreviados: E), de Emanuela Cresti (abreviada: C) e de Massimo Moneglia (abreviado: M).

\section{PRIMEIRA PARTE: Fala e escrita}

E.: Qual é, do ponto de vista linguístico, a diferença principal (ou as diferenças principais) entre a linguagem veiculada através da fala e a linguagem transmitida através da escrita?

C.: Essa poderia parecer, à primeira vista, uma pergunta errada. Temos, hoje em dia, tantos estudos de matriz variacionista, principalmente aqueles de Biber, só para citar um nome importante, segundo os quais haveria um continuum no qual se desenvolvem textos e produções intermediários entre a fala e a escrita (chat, blog e outras tipologias). Digamos que eu não compartilho essa visão.

E.: Se entendo bem, você não a compartilha porque você não acredita nessa ideia de continuum.

C.: Sim. Eu acho que, quase todas as vezes que, em linguística, se propõe a ideia de continuum, quer dizer que não se sabe oferecer uma verdadeira resposta a um problema definido. Mas nós não somos obrigados a dar uma resposta. Podemos deixar o problema em aberto e dizer que os instrumentos em nossa posse não permitem ainda chegar a uma resposta satisfatória. É o que acontece comumente em ciências mais maduras. Pode-se dizer, simplesmente, que precisamos de informações e dados não disponíveis no atual estado da arte antes de achar uma solução.

Mas, voltando à questão da pergunta, podemos também seguir uma outra linha clássica (na Itália, representada, por exemplo, pelos estudos de Carla Bazzanella ${ }^{2}$ ), que identifica a principal diferença entre fala e escrita em três macroestruturas de base: o meio de transmissão; o tipo de relação entre autor e destinatário; o tipo de relação que o momento da enunciação tem com o contexto. E daí decorrem consequências muito grandes e numerosas: as ondas sonoras e o ar de um lado, a grafia e o sinal visual de outro; isso implica em habilidades diferentes, a instabilidade da primeira modalidade versus a estabilidade da segunda; a diferente relação com

\footnotetext{
2 Linguista italiana. Entre as suas publicações principais, lembramos Le facce del parlare. Un approccio pragmatico all'italiano parlato, Firenze, La Nuova Italia, 1994 e C. Bazzanella, Emotions, Language, and Context, in Emotion in Dialogic Interaction, a cura di E. Weigand, Amsterdam, John Benhamins Publishing Company, 2004, pp. 55-72.
} 
as categorias de espaço e de tempo; a interação afetiva e pragmática são completamente diferentes; as proeminências contextuais são compartilhadas em um caso e não em outro. Enfim, seguindo esse caminho podemos escrever um excelente capítulo de livro.

Contudo, a meu ver, também seguindo esse caminho perdemos de vista uma questão mais profunda, que é a que torna a pergunta especialmente interessante e apropriada. Fala e escrita, a meu ver, respondem a duas concepções diferentes da linguagem em um sentidó que se tornou mais claro para mim acompanhando as reflexões introduzidas cerca de dez anos atrás por Massimo Fagioli ${ }^{3}$ sobre o conceito de linha.

A capacidade de conceber e traçar uma linha é própria unicamente dos seres humanos, ou seja, é uma capacidade da nossa espécie. A linha não existe na natureza. É algo que somente nós somos capazes de idealizar, de imaginar. É uma modalidade de externalização do nosso pensamento. Isso é muito importante. Eu mesma, por muitos anos, expressei a opinião de que a língua escrita derivasse da língua falada. De fato, do ponto de vista filogenético, podemos dizer que o homo sapiens surge por volta de 120.000 anos atrás (e que, com ele, nasce a fala), enquanto as mais antigas formas de escrita surgem por volta de 5.500 anos atrás. E, do ponto de vista ontogenético, primeiro aprendemos a falar e somente muito depois podemos, eventualmente, aprender a escrever.

E.: E também, a escrita é apreendida graças a um treinamento e a uma forma de ensino, enquanto a fala é apreendida espontaneamente.

C.: Sem dúvida. Por isso a ideia é que a escrita derive da fala. Contudo, essa derivação deve ser melhor circunstanciada. Provavelmente, não é por acaso que temos cerca de 120.000 anos de língua falada, com a formação das diferentes línguas, e que, a um certo ponto, chegou-se à formação de sociedades complexas com uso complexo, social, da linguagem e ao surgimento da escrita. Mas essa possibilidade de transformar a linguagem falada em linguagem escrita não é uma operação banal.

\footnotetext{
${ }^{3}$ Psiquiatra italiano que se dedicou a estudos sobre os conceitos de representação, forma e linguagem. Sobre o tema citado na entrevista, vejam-se os trabalhos: Facchini S. \& Sani F. (eds.) 1998, Immagine della linea, Atti del Convegno Immagine della linea (26 ottobre Firenze 1996), Roma: Nuove Edizioni Romane; Fagioli M. \& Fagioli F. 2000, La psiche oltre Freud. Dibattito (Convegno Uomo, natura energia, agosto 1999 Palau), in Il sogno della farfalla, 1, Roma: Nuove Edizioni Romane, 14-40.
} 
Os dois principais sistemas de escrita são aquele ideográfico-logográfico e aquele alfabético. Ainda assim, sabemos que, na origem dos sistemas de escrita, temos sempre um sistema ideográfico. Por quê? Porque esse sistema reproduz, por analogia, objetos do mundo. Isso pode parecer banal, mas o fato de nós podermos utilizar figuras para representar coisas é algo de absolutamente único da nossa espécie. Nenhuma outra espécie desenha. Também é considerado um salto fundamental na história da nossa espécie o fato de, a um certo ponto (tradicionalmente por volta de 50.000 anos atrás mas agora parece também antes), começarmos a achar os grafites e as pinturas rupestres. Esses produtos coincidem com um salto cultural importante. Enfim, a escrita alfabética se baseia no significante, na capacidade de reproduzir sons e, portanto, é completamente abstrata se comparada com uma escrita ideográfica, que representa diretamente o significado através de uma representação. Mas essa diferença entre os dois sistemas ainda não nos explica o surgimento da escrita.

Primeiro, temos que considerar a capacidade de representar através de imagens. Essa é uma habilidade a ser explicada. Por outro lado, hoje, mesmo os sistemas que são ditos ideográficos, como o sistema de escrita chinês, de ideográfico não mantêm mais nada. Tornaram-se completamente convencionalizados. Aliás, o chinês é uma língua que apresenta características particulares: é uma língua isolante, uma língua em que a homofonia é um problema importante para a interpretação. É um pouco como se o sistema gráfico, que não é mais analógico, mas que continua se baseando em uma representação figurada do significado, levasse a consequências também na estruturação da língua. sabemos É sabido, por exemplo, que o fato de existir, na história da linguagem, primeiro a escrita contínua, depois a pontuação, depois a imprensa etc. leva a uma forte evolução estrutural da linguagem, por exemplo, na sintaxe. É como se a modalidade escrita condicionasse também a evolução de uma língua.

Por outro lado, temos a fala, que se apoia em uma representação de uma imagem mental, sendo ela também típica dessa capacidade imaginativa da nossa espécie. Uma capacidade de imaginar que é possível também com uma separação do que é a experiência. Ou seja, entre a experiência, e portanto toda a nossa bagagem fisiológico-sensorial, e a nossa capacidade de imaginar, há um salto que não parece existir da mesma maneira em outras espécies. Trata-se de uma capacidade de imaginar que é criativa. Ela não nasce do nada, a experiência sensorial é necessária, mas a criação da imaginação é algo a mais, não redutível à experiência. E aqui sim, que há um salto. 
E.: Mas então, para ver se entendi direito, a escrita, entendida como escrita linguística, seria fruto do cruzamento de uma capacidade humana que é independente da linguagem articulada, ou seja, a capacidade de representar através de linhas, e portanto de figuras, e a presença da linguagem articulada.

C.: Não sei. Essa é uma questão grande. Em princípio eu diria que não, porque esses grafites que conseguimos encontrar de várias dezenas de milhares de anos atrás parecem ser devidos a um estágio em que a linguagem já existia.

E.: Recentemente foram achados sinais da capacidade representativa de homens bem mais antigos do que a tradicional datação da linguagem. Talvez isso leve também a uma retrodatação da linguagem. Mas, o que me parece interessante é que você individualiza uma capacidade, aquela de representar através de linhas, que é claramente conectável à escrita, mas não à fala. Afinal, não é suficiente apenas a fala para explicar a escrita. Essas reflexões de Fagioli limitam a dependência da escrita à fala. Acabam atribuindo à origem da escrita a necessidade de algo que não se reduz à capacidade de falar. E uma outra questão é o que nós chamamos de linguagem. Do que precisamos exatamente para que exista a linguagem? Qual o papel, por exemplo, da comunicação gestual?

C.: Sobre isso, gostaria de dizer que, quando eu falo de linguagem, refiro-me à transmissão de conteúdos de pensamento, e essa transmissão, evidentemente, no começo e por muito tempo foi só oral. A comunicação é um estímulo fundamental para falar e para conceber e configurar, no tempo, a linguagem, mas o ponto de partida é o pensamento humano, com essa característica de ir além da experiência, acrescentando aspectos a mais àqueles que a experiência oferece. Aquilo que, em filosofia, foi chamado "a criação do novum", a criação da novidade.

Portanto, nós temos essa capacidade e ela conduz à criação da linguagem graças a uma pulsão afetiva, uma vontade de se relacionar com os outros e de comunicar essa nossa realização de pensamento.

Temos, naturalmente, várias contribuições interessantes de tipo diferente sobre a origem da linguagem, como aquela que a correlaciona ao canto da mãe que, quando deve ficar longe da criança, canta para sinalizar que está presente, ou outras ainda. Naturalmente. a linguagem 
se apoia também em necessidades práticas. Mas o fato de que fomos capazes de desenvolver a linguagem e chegar a formas tão ricas depende claramente da nossa capacidade de pensamento.

Quanto a essa relativa autonomia da escrita em relação à fala na proposta de Fagioli, isso foi algo, pra mim, difícil de aceitar. Mas sim, a relação da escrita com a linguagem passa por uma habilidade, aquela de traçar linhas, que não é imediatamente correlata à fala.

Nós temos características anatômicas que nos permitem articular sons sofisticados, existem fatos rítmico-musicais talvez anteriores à linguagem, há toda uma evolução anatômica ligada ao bipedismo e às suas vantagens práticas em termos evolutivos. Enfim, nós nos apoiamos nas nossas dotações anatômicas para alcançar uma linguagem que possui características entonacionais de base, devidas a uma fase anterior ao desenvolvimento da linguagem na sua completa expressão. Ainda assim, a motivação para criar um sistema tão complexo me parece ser a vontade de transmitir esses nossos conteúdos de pensamento.

Naturalmente, antes de chegar a formas minimamente consistentes de escrita é necessário um longo percurso de civilização. Só que a escrita não pode ser considerada simplesmente uma transposição mecânica da fala, porque se apoia em uma outra capacidade humana, que também é antiquíssima, que é aquela de traçar linhas com as quais representamos o mundo. Mas é sempre o mundo assim como nós o pensamos. Usar essa capacidade para apoiar nela a linguagem é algo a mais que uma simples transposição utilitária da fala. E a escrita, além de influenciar o desenvolvimento das línguas com base em diferentes sistemas de escrita, permite também um uso da língua que é diferente, levando a formas não concebíveis sem a escrita, como, por exemplo, o romance ou a lírica. É difícil imaginar a lírica sem a escrita. Podemos, talvez, imaginar os ciclos épicos sem a escrita, graças às rimas, ao acompanhamento musical, à função de transmitir para as novas gerações fatos, genealogias e valores. Mas a lírica, é necessário escrevê-la. E isso vale para vários tipos de textualização, como os textos religiosos, os códigos legislativos, entre outros.

E.: E a esse ponto entram em cena também razões sócio-históricas e a escrita se torna uma tecnologia.

C.: Sim, claro. Contudo, conceber certas formas é possível somente com a escrita. Mas, voltando à pergunta inicial, certamente existe a diferença de meio, o uso da voz e da linha, 
porque o pensamento adquire formas diferentes. Por isso, para mim, também o chat, o blog, com todas as suas peculiaridades, são sempre língua escrita.

M.: Gostaria de dizer algumas coisas de um ponto de vista diferente. Coisas mais conhecidas quanto à relação entre fala e escrita. Refiro-me à diferente relação que a fala e a escrita possuem com a expressão corporal. Na fala, a expressão corporal é presente em todos os níveis, a partir da voz, e depois com as expressões faciais, a gestualidade, a proxêmica. Mas não se trata só da multimodalidade; trata-se já, em si, de um aspecto da voz, com toda a estratificação que existe dentro da voz, da emoção até a expressão do vários domínios governados prosodicamente. $\mathrm{O}$ fato de que já na voz exista toda essa estratificação é significativo. Mesmo a nossa conversa atual, que é mediada através doSkype, contém referência ao corpo.

C.: Eu estava gesticulando quando falava.

M.: Sim, mas naquilo não havia nenhum significado.

E.: Mas a Cresti falou uma coisa fundamental segundo $\mathrm{McNe} \mathrm{ll}^{4}$. Nós não falamos sem gesticular. É verdade que eu não podia vê-la. Mas isso significa que tem uma inseparabilidade entre a fala e o corpo, mesmo quando não existe um sentido para o gesto do ponto de vista comunicativo.

M.: Sim, isso é uma outra vertente da questão. De fato, a fala é assim. Isso nos leva a nos perguntar o porquê dessas modalidades serem síncronas. Por que todas as modalidades com as quais a fala se realiza (voz, expressão facial, gesto, corpo) são síncronas? São síncronas porque dependem todas do mesmo tipo de impulso. Essa é uma característica neurofisiológica mas também interacional, se esse estímulo é colocado na relação. É um fato dinâmico. Mas o fato de todas as manifestações da linguagem falada serem síncronas, a partir do pensamento, é um desvio com respeito ao que eu queria dizer. Eu queria dizer que a expressão corporal está dentro do sinal vocal, o que leva a uma forte consequência do ponto de vista do significado. Todo o significado natural, em termos griceanos, está dentro o significado não natural. O significado

\footnotetext{
${ }^{4}$ Entre a riquíssima produção de Mc Neill, veja-se, pelo menos, How Language Began: Gesture and Speech in Human Evolution. New York, USA; United Kingdom: Cambridge University Press, 2012.
} 
natural é aquele que não é baseado em signos, porque você não reconhece a minha intenção de significar; e a fala contem tanto o significado natural quanto o significado não natural. Se eu fico vermelho quando digo algo, eu estou comunicando, por exemplo, vergonha, mas sem a intenção de comunicá-lo. Isso não é possível para a escrita. Na escrita, as modalidades de realização do sinal não entram da definição do significado.

E.: Poderíamos dizer que isso seria diferente nos precursores da escrita, segundo a interpretação de Fagioli? Ou seja, poderíamos dizer que os desenhos podem receber um significado mesmo sem ter a intenção de comunicá-lo?

C.: Eu acho que, na base de toda a atividade linguística, a intenção comunicativa permanece. Aquele que escreve uma lírica, mesmo se o faz na casa dele e sozinho, o faz para comunicar algo. E assim também aconteceu com os antigos humanos que desenharam os animais dentro da caverna. A dimensão comunicativa existe sempre. Nesse caso, é independente da interação, mas existe uma intenção comunicativa de conteúdo de pensamento. A falta de intenção comunicativa é possível somente em algo muito marginal, como quando estou no telefone escutando a musiquinha de espera para poder falar com alguém do call center e acabo rabiscando algo num pedaço de papel para descarregar a tensão. Mas, nesse caso, a atividade de desenhar é uma atividade qualquer, como enrolar papel ou roer unhas. Quando existe um empenho criativo, sempre há uma vontade de comunicar. O sofrimento do artista não reconhecido seria um testemunho dessa vontade comunicativa.

\section{SEGUNDA PARTE. Fala e escrita na tradição linguística}

E.: Na tradição linguística, há uma tendência de não considerar as diferenças existentes entre as modalidades falada e escrita como suficientes para propor unidades de análise diferentes para cada modalidade, o que traz consequências para a análise da linguagem. Como explicar as dificuldades da tradição linguística em captar as diferenças entre a fala e a escrita?

M.: Há uma resposta muito simples, pode-se dizer banal, para essa questão. Para refletir sobre os objetos, esses devem possuir uma representação permanente, o que é uma necessidade da reflexão consciente. Essa reflexão consciente sobre a linguagem opera necessariamente sobre os objetos escritos, até mesmo pela característica intrínseca da oralidade, que não é permanente. 
Essa reflexão consciente só começa a existir para os objetos orais quando, no fim do século XIX, se torna possível haver a permanência do sinal oral através de diversas técnicas de gravação.

E.: Isso quer dizer que a possibilidade de registro é necessidade básica para a reflexão sobre a linguagem?

M.: Bem, se pensarmos nas primeiras reflexões sobre a linguagem, há três, quatro séculos antes de Cristo, nas reflexões de Platão e Aristóteles, essa necessidade da permanência não parecia ser assim tão fundamental. Não porque não existisse escrita, mas porque na oralidade, em especial na retórica, a relação entre a linguagem e a fala se configurava de modo diferente em relação às reflexões posteriores.

C.: Mas as reflexões de Platão e Aristóteles são filosóficas e buscam compreender a relação entre pensamento e linguagem; não se ocupam propriamente de aspectos gramaticais. As primeiras gramáticas, de quatrocentos, quinhentos anos antes de Cristo, nascem para codificar e registrar a língua dos Vedas, os textos sagrados indús. E a primeira gramática de Dionísio da Trácia foi feita para manter a norma do grego clássico, especialmente para permitir a leitura da Ilíada e da Odisseia. Ou seja, as primeiras grandes reflexões sobre a linguagem, que originaram tratados gramaticais, foram feitas sempre com base em textos escritos fundamentais.

M.: Sim, mas, mesmo que em Platão e Aristóteles não haja uma reflexão gramatical no sentido estrito, encontramos referência a formas de identificação das categorias dos nomes e verbos, por exemplo. Esses conceitos fundamentais de reflexão linguística não me parecem ser assim tão separados na forma oral e na forma escrita.

E.: Então, seria correto afirmar que, por um lado, o estudo da linguagem nasce para permitir a compreensão de textos considerados importantes, e, por outro lado, há uma reflexão sobre a linguagem independente desse fato?

C.: Sim, claro, e essas duas visões não estão em oposição. 
M.: De minha parte, acredito que a reflexão sobre a linguagem se dá principalmente sobre a linguagem escrita, porque existe a necessidade da permanência do objeto para a sua perceptibilidade, e a língua escrita assegura essa exigência. Já na língua falada, por sua própria natureza, isso não acontece. É preciso estar atento ao fato que, na linguagem poética, que é, em sua origem, oral, não era possível utilizar formas de objetificação próprias do pensamento grego, isso pelo próprio caráter rítmico e musical dessas formas, que se transmitiam muito mais pelo canto. E é através do canto, da memorização dos objetos cantados e rimados, que se obtém uma permanência da oralidade e, com isso, se permite alguma reflexão sobre a linguagem oral.

E.: E essas formas poéticas, ao permitirem a memorização, permitem a fixação e, com isso, perde-se a dimensão interativa da linguagem. Então, essas reflexões não estão ligadas à dimensão interativa, mas à dimensão estática da linguagem.

C.: Verdade. Mas, mesmo assim, não foi dessas formas de linguagem poética que se originaram gramáticas ou mesmo reflexões filosóficas sobre a linguagem. O pensamento filosófico grego que se apoia no uso da modalidade oral, parece-me, é aquele de base política e social. Isso porque na vida civil da polis era preciso saber falar, fazer discursos. Ou seja, havia uma pesquisa sobre o discurso político, sobre a capacidade de compreensão, sobre a retórica, que traz uma reflexão sobre a modalidade falada. Mas esse é um uso particular da língua falada. E, além do mais, a partir daí não se chega a generalizações sobre as entidades linguísticas, como gramáticas. As gramáticas necessitam de textos escritos.

E.: Mas antes das técnicas de gravação modernas não havia outras reflexões sobre a língua falada?

C.: Isso é muito interessante, porque no começo do século XIX, na Alemanha, se inicia uma reflexão sobre a língua falada, com Weil e Gabelenz, entre outros. E o mais interessante é que se torna possível começar a retomar as reflexões sobre a língua falada depois que se conhecem centenas de línguas diferentes ao redor do mundo e que, sobre essas línguas, são feitas gramáticas. É como se tivéssemos conhecimentos consistentes que, de alguma maneira, permitem que se comece a refletir sobre essa entidade fugaz. Mas, como bem disse o Massimo, o estudo efetivo da língua falada acontece somente depois da Guerra, quando se começa a 
gravar a fala com o magnetófono, até que, nos anos 90, os computadores permitem a gravação do som sem limites, o que antes não era possível.

\section{TERCEIRA PARTE. Tradição lógica e tradição empírica. O estudo das ilocuções.}

E.: Quais seriam as vantagens e os méritos da tradição lógico-formal do estudo da linguagem e quais as suas limitações?

M.: É importante citar os trabalhos seminais da descrição lógica da linguagem, ou seja, a semântica fregueana, a semântica tarskiana e a lógica modal intencional. Esses são considerados os três marcos que, no início do século XX, deram início ao desenvolvimento da descrição lógica da linguagem, que trata da abordagem fundamental do significado. Se pensarmos nas abordagens sobre o significado, não se pode desconsiderar essas tradições. $O$ mérito fundamental dessas abordagens em relação às teorias precedentes é esclarecer alguns aspectos sobre a interpretação. O que quer dizer "interpretar"? Interpretar significa associar uma denotação aos enunciados ou às palavras, e associar uma denotação a uma proposição significa estabelecer seu valor de verdade. Esse fundamento se relaciona à ideia de que o sentido das expressões não é equivalente à sua referência. Este é o fundamento fregueano da Semântica, a ideia de que o sentido das expressões é o "modo" com que, através da denotação, se representa o conhecimento das "condições". Isso porque, para saber se uma proposição é verdadeira ou falsa, é preciso ter o conhecimento sobre as condições que fazem com que um objeto possa ser uma denotação de um predicado. Esses conceitos simples encontraram uma correspondência formal na tradição lógica do início do século XX. E, portanto, substancialmente, na semântica Tarskiana, além de outras tantas semânticas, até a formalização da lógica modal. Na verdade, mesmo a lógica modal sendo um conceito medieval, a sua formalização é muito recente, dos $\operatorname{anos} 60$.

E.: Então essa formalização foi um passo importante para o avanço dos estudos linguísticos.

M.: Sim, porque, com ela, veio a possibilidade de tratar os contextos modais de forma sensata, do ponto de vista de assegurar a compreensão das condições de verdade dos operadores. A tradição lógico-formal levou ao conhecimento sobre alguns aspectos precisos da linguagem, como os quantificadores e a possibilidade de distinguir as condições de verdade nas estruturas 
coordenadas e nos diversos tipos de subordinadas; enfim, a explicitação das condições de verdade em relação a diversos tipos de estruturas sintáticas.

E.: Poderia citar outros exemplos?

M.: Também trouxe um grande avanço na compreensão da pressuposição, que antes era um conceito muito vago e se tornou um conceito bastante claro. E também os conceitos relacionados à semântica aspectual, importante para a compreensão dos tempos verbais. Ésses conceitos eram extremamente obscuros nas tradições anteriores e se tornaram absolutamente claros na tradição lógico-formal. Além disso, também os diversos tipos de conjunções e, claro, naturalmente, o componente semântico presente na descrição das partes do discurso. Certamente, por essa série de conceitos, a tradição lógica tem um mérito gigantesco com respeito à tradição precedente, pois foi como passar do escuro para o claro.

E.: E quais seriam então as principais limitações dessa tradição?

M.: Eu diria que as limitações maiores estão na possibilidade de estudar e explicar o léxico. Quero dizer, em teoria, sim, é possível explicar o significado de uma expressão lexical com base na tradição lógico-formal. Isso porque ela se adapta bem à ideia de conhecer as condições em relação às quais uma denotação pode ser aplicada a um predicado. Por exemplo, se eu digo "aquela é uma cadeira" o sentido da expressão "cadeira" é contido nas condições que eu atribuo para que algo possa ser considerado uma cadeira, ou seja, se tem assento, se tem pés, se alguém usa para sentar, etc. Então, em teoria, se pode aplicar essa ideia do conhecimento sobre as condições para compreender o léxico. Só que, na tradição lógica, não houve uma ampliação desse conhecimento aplicado no léxico e, logo, sobre o sentido das expressões lexicais.

E.: E por que esse aprofundamento não ocorreu?

M.: Eu diria que por causa de um preconceito filosófico, que vem da ideia da impossibilidade do conhecimento sobre certas dimensões do pensamento. Utilizo o termo de Quine, que foi um filósofo importante e que influenciou, de forma indireta, a forma das gramáticas gerativas. Então eu considero uma lacuna nessa tradição o estudo do léxico. Os resultados sobre o estudo 
do significado lexical, dadas as premissas teóricas, são extremamente reduzidos. E isso não é decorrência da construção da teoria e do seu fundamento lógico, mas de alguns preconceitos embutidos na filosofia que os estudiosos adotam.

E.: E quanto ao estudo dos atos linguísticos?

M.: É bastante diferente o que aconteceu no estudo das ações linguísticas. É claro que é a partir da tradição da lógica filosófica que se evidencia a característica específica das frases performativas e, com isso, a noção clara de ato linguístico. E isso não é pouco. Mesmo Austin, ainda que não fosse um lógico, conhecia muito bem a lógica da filosofia oxfordiana. Mas é preciso reconstruir, a partir da tradição lógico formal, os conceitos necessários para a análise da linguagem. O estudo das ações linguísticas não apresenta nenhuma relação com o estudo da forma lógica, porque não há uma lógica das diversas ações linguísticas.

C.: Mas também precisamos considerar que os estudos sobre as condições e toda a tradição gramatical são estudos sobre a língua escrita. Na língua escrita, há uma predominância de frases de tipo assertivo, e isso, eu creio que teve seu impacto nos estudos das ações linguísticas. As afirmações de Austin, da década de 50, só puderam ser confirmadas mais tarde, depois dos anos 90, com a criação de grandes corpora de língua falada e com o alinhamento do som ao texto, com a associação de valores prosódicos a valores acionais e etc. é que emerge esse dado incontestável: que a língua falada é caracterizada pela acionalidade, e não pode ser reduzida à frase sintática correspondente à proposição semântica.

E.: Mas existe uma tradição de estudo da ilocução em termos lógicos. Refiro-me a Searle e, em particular, a Vanderwecken. O que resulta dessa tradição do estudo das ilocuções em termos lógicos?

M.: Eu diria que, no estado atual, resulta em muito pouco, porque, hoje, o interesse maior é em compreender quais são as atividades ilocutórias que, de fato, se realizam na linguagem natural. E o estudo de atividades ilocutórias a partir do léxico não nos traz nenhum conhecimento sobre a sua consistência natural dentro da linguagem falada. Podem-se ver muitos atos locutórios representáveis lexicalmente em frases performativas para as quais simplesmente não há 
correspondência na fala natural, pois não se encontra uma correspondência prosódica. Logo, é um fato lexical, então não é interessante para o estudo das ações linguísticas. É claro que Searle tem seus méritos, como, por exemplo, a ideia de que todos os atos linguísticos possíveis podem ser enquadrados dentro de classes de um número limitado.

C.: Sim, são exatamente os princípios usados para determinar as classes ilocutórias que são interessantes: como a direcionalidade, o escopo, as condições de felicidade etc. Isso nos dá ferramentas para a identificação de quais são os traços pragmáticos envolvidos na acionalidade ilocutória. Mas é o quadro geral do Searle que não corresponde ao objeto.

M.: E, principalmente, não corresponde a uma lógica. Ou seja, não corresponde a um raciocínio que, a partir de premissas, chega-se às consequências. A questão da acionalidade não tem nada a ver com um sistema de regras que levam a consequências necessárias.

E.: Então é a ação que não é reduzível a termos lógicos?

M.: Sim. Eu não consigo entender o que seria a lógica da conclusão com relação à lógica do convite, por exemplo.

C.: Seria como procurar a lógica do soco. Qual é a lógica do soco? Qual é a lógica da ação de escovar os dentes?

M.: São ações e, portanto, o estudo é de tipo naturalístico e empírico. Assemelha-se mais com o tipo de estudo da biologia. São estudos naturais/culturais. Não por acaso os instrumentos de análise são de caráter natural e são encontrado na voz. Não tem muito a ver com a lógica.

E.: Em que sentido se pode diferenciar as ações verbais e as ações não verbais?

C.: Primeiro, é preciso entender o que se quer dizer com ações verbais e não verbais. A distinção que interessa para o estudo e classificação das ilocuções é aquela entre as ações que são primariamente comunicativas, mas que não são linguísticas, e as ações linguísticas. 
E.: Mas é possível explicar a relação entre ação no sentido geral e ação no sentido linguístico?

C.: Para mim, quando a ação não tem nenhuma intenção interativa com o interlocutor, quando a ação é, digamos, automática, como para operar uma máquina, dirigir ou cozinhar, a relação com o pensamento é limitada, é restrita às habilidades e conhecimentos do indivíduo. Mas eu, particularmente, que parto da base da língua falada, considero que a linguagem tem como característica fundamental ser a formalização de uma realidade do pensamento, a qual serve para exprimir uma comunicação com o outro. Esses dois aspectos são intimamente relacionados, e logo, a linguagem é ligada à intencionalidade afetiva para com o outro. Pensamos uma certa coisa, de uma certa maneira, e isso se transforma em uma certa ação para comunicá-la de um determinado modo ao outro. A ação linguística então é concebida de modo complexo: é o pensamento formalizado e veiculado através de um certo tipo de intenção em relação ao outro. Por exemplo, se estou cozinhando, entra em jogo a minha habilidade, uma intencionalidade de realizar a ação, mas não há essa operação de conceitualização, formalização de pensamento, veiculação através da afetividade dirigida ao outro. Então, não há as características fundamentais da ação comunicativa. São coisas muito diferentes.

M.: Mas para chegarmos a uma definição do que é uma ação linguística e do que é uma ação comunicativa, a partir do entendimento mais básico sobre o que é uma ação, é preciso ter claro em que nível iremos definir o que é uma ação, ou seja, que tipo de definição de ação utilizamos. Eu trabalhei durante metade da minha carreira sobre essa questão e divido a minha experiência em dois momentos. Um é relacionado à aquisição, à ontogênense do comportamento comunicativo pelas crianças. E o outro se trata de um ponto de vista modelístico. Esses são dois pontos de vista muito diferentes.

Do ponto de vista da ontogênese, uma coisa muito interessante de notar é que a ação sobre os objetos e a ação interpessoal são dois canais, no início, muito separados um em relação ao outro. Todos os estudos, como os de Piaget, mostram que, no primeiro ano de vida, esses dois canais não se integram, pelo menos até os sete ou nove meses. Quando esses canais se integram, ocorre uma mudança perceptível, no comportamento, da relação entre a criança e o objeto. Antes disso, de um lado, existe a relação entre a criança e a mãe ou o cuidador. Há uma série de comportamentos da criança em relação à mãe ou cuidador, como a sucção, como ficar colado no cuidador, segui-lo com o olhar, emitir chamamentos, ações de caráter vocal, mexer- 
se quando vê a pessoa etc. E, ao mesmo tempo, há a interação da criança com os objetos, como segurar, girar, acompanhar seu movimento. Mas essas ações da criança para com o cuidador e da criança para com o objeto não se integram umas com as outras até por volta dos sete, oito meses de idade, que é justamente quando começam as primeiras ações comunicativas. Essas ações se integram substancialmente através de gestos dêiticos, como apontar.

Eu quero esclarecer aqui que esse raciocínio que faço deveria ser completado com o conceito de ideação, desenvolvido pela Emanuela. A emergência das ideias na criança é caracterizada pela emergência dos símbolos verbais, no primeiro ano de vida.

C.: É preciso esclarecer este ponto. O que falta à criança é a ação específica de formalizar o pensamento em uma produção vocal. Quando a criança balbucia, faz simplesmente exercícios com os fones. Mas quando a criança produz, por exemplo, "ma-ma", com duas sílabas de durações diferentes, querendo dizer "mamãe", então ela produziu um símbolo verbal. A criança é dotada de formas de pensamento e imaginação desde o momento em que nasce, mas lhe falta essa capacidade específica de tomar um pensamento, que é vago, difuso, e traduzi-lo em um sinal vocal que é formalizado para comunicá-lo ao outro. Eu permaneço convicta de que há uma estreita e necessária relação entre a ideação linguística e a sua comunicação.

M.: O momento fundamental é aquele em que se coordenam a atividade comunicativa e a atividade simbólica. O pensamento que possui expressão verbal, que vem utilizado com finalidades comunicativas e realizado em atividades comunicativas nasce com o ato linguístico.

C.: $\mathrm{O}$ ato linguístico como atividade intencional acontece somente quando se coordenam atividade simbólica e atividade comunicativa. A criança diz "mãe" porque alguém está ali. Nesse caso não realiza uma ação comunicativa codificada. As perguntas, por exemplo, só acontecem depois dos dois anos.

M.: O que dissemos é mais uma série de reflexões do que uma verdadeira resposta. De toda maneira, é interessante refletir sobre o conceito de ação comunicativa e ação linguística com relação à ontogênese.

C.: Sim, porque faz perceber as naturezas distintas de diferentes tipos de ação. 
E.: E sob o segundo ponto de vista?

M.: Sob o ponto de vista modelístico, definir o que é ação significa formular um conceito. A ação consiste em um modelo, um padrão de modificação do mundo. Dizer que é um padrão significa dizer que é algo repetível, reproduzível, e o fato de ser uma modificação do mundo é central. Esse modelo tem a característica de permanecer o mesmo, independentemente de quem seja o agente, ou seja, quem quer que seja aquele que realiza a modificação do mundo. A outra característica é que a série de "coisas" que podem ser objetos dessa ação podem ser modificadas. Segundo esse conceito, a ação física, como folhear um caderno, e uma ação como, por exemplo, perguntar “Como vai?" podem ser definidas do mesmo modo, como padrões de modificação do mundo. Basta incluir na definição de "mundo" a esfera da comunicação. Ambas modificam o mundo, então, desse ponto de vista, ambas são ações, tanto a não linguística quanto a linguística. Mas as ações linguísticas e comunicativas são tipos especiais de ação.

C.: Resta diferenciar o que são as ações comunicativas que não são linguísticas das ações linguísticas. As ações linguísticas são todas comunicativas. A questão é identificar um domínio de ações comunicativas que não são linguísticas. Uma deixis ou uma negação ou outras ações podem ser feitas sem se dizer nada, como apontar o dedo ou balançar a cabeça. São ações comunicativas convencionais e reconhecíveis. Segundo minha análise, nessas ações comunicativas há a vontade, o afeto que rege a ação, e um modelo de ação convencionalizado, ainda que primitivo, expresso através do gesto. Mesmo essas ações "primitivas", por serem convencionalizadas, exigem um grau de elaboração, visto que crianças autistas ou com retardo não as fazem, ou as fazem muito mais tarde que as outras crianças. De qualquer modo, nessas ações comunicativas não ocorre a formalização de um ponto de pensamento traduzido em um sinal vocal. As recusas ou a dêixis podem ser feitas de modo não verbal, mas a linguagem falada é o nível máximo de elaboração.

E.: Existem ações que são somente não linguísticas, ações que são somente linguísticas e ainda ações que podem tanto ser feitas de modo não linguístico, através de uma forma qualquer de convencionalização, ou de modo verbal. Pode-se dizer que a aquisição da linguagem, seja do 
ponto de vista ontogenético, seja do ponto de vista filogenético, amplia significativamente a quantidade de ações que é possível realizar?

C.: Sim, isso me parece evidente. A linguagem é dos veículos fundamentais da socialização e civilização.

E.: Podemos dizer então que a ação, naturalmente, é preexiste em relação à linguagem, mas a linguagem aumenta enormemente a esfera da acionalidade.

E.: Tanto a ação como a comunicação são amplamente possuídas por todos, desde os neandertais, os bonobos e outras espécies. Certamente os neandertais possuíam alguma forma de linguagem, alguma capacidade de pensamento imaginativo, mas provavelmente não como a nossa.

M.: Penso sempre, quando reflito sobre esse tema, sobre a questão da filogênese. Em relação aos neandertais, de uma parte, nega-se vigorosamente que apresentassem alguns aspectos do pensamento da nossa espécie, como a ideação, que se considera própria do homo sapiens sapiens. De outra parte, paralelamente, estudos feitos nos anos 50 e 60 mostravam que o ângulo da cabeça em relação ao osso occipital não poderia permitir uma glote e uma laringe como a nossa. Isso quer dizer que, provavelmente, não poderia fazer articulações finas dos sons, como são próprias da linguagem verbal.

Levando isso em consideração, vê-se que há duas características importantes para a definição da linguagem. Uma é aquela do ponto de vista fisiológico, que possibilita a articulação dos sons e, logo, da fonologia das palavras. Mas, por outro lado, a criança, mesmo enquanto não pode articular um número muito grande de sons, não está impedida na sua capacidade de se comunicar, pois se comunica de qualquer modo, usando sílabas, ainda que pouco articuladas. A articulação fina dos sons acontece através de um percurso muito definido: balbucio, balbucio reduplicado, balbucio variado, pseudopalavra com acento e finalmente coordenação com os símbolos. O aspecto fonológico é importante na definição da atividade linguística, pois, como se sabe, uma característica própria da linguagem é a dupla articulação. Mas isso não tem muito impacto na comunicação básica, porque se pode comunicar mesmo sem a dupla articulação. Se vamos em direção à sintaxe, a possibilidade de haver uma articulação fina dos sons em unidades 
tonais é um dado relevante para a definição da linguagem e que a separa facilmente de todos os outros sistemas comunicativos.

\section{QUARTA PARTE. A sintaxe na fala e na escrita.}

E.: Qual é o papel da sintaxe na fala e como se deve analisá-la na fala e na escrita?

C.: O que entendemos com sintaxe? Existe uma ideia muito geral segundo a qual sabemos que as palavras não são isoladas, mas se combinam. Agora, durante o séc. XX e, principalmente, com o estruturalismo americano de Bloomfield, Harris e depois Chomsky e Jackendoff, tivemos uma descoberta fundamental, que é o conceito de sintagma, que permite entender o esquema de composição das palavras nas línguas. Então, o conceito de sintagma é algo diferente do conceito de sentença.

E.: Você está se referindo ao conceito de núcleo com as suas projeções.

C.: Sim. Na teoria X-barra, o núcleo é dominado por um especificador e acompanhado por uma regência ou argumento; com a possibilidade de modificadores. Os especificadores, no caso de um núcleo nominal, são quantificadores ou identificadores, em um núcleo verbal são especificadores de tempo, de aspecto ou modalidade. A regência também muda se temos núcleos nominais ou verbais. Então, temos uma estrutura hierárquica e temos a recursividade. Esse, pra mim, é o resultado maior do estruturalismo e também do gerativismo (mas depois o gerativismo seguiu também outras direções). Então, quando eu falo de sintaxe, refiro-me a essa estrutura.

Voltando também ao que dizia o Massimo, ou seja, que a linguagem humana tem algumas características, como a dupla articulação e essa estruturação sintática hierárquicorecursiva, essas são características específicas da linguagem humana e que não são determinadas por uma finalidade de tipo comunicativo. Daí a afirmar que são genéticas há uma distância grande. Mas, provavelmente, são universais linguísticos.

M.: Por exemplo, essas características não são presentes nas linguagens lógicas. São características da linguagem natural. Na linguagem lógica, a dupla articulação não existe. E a estrutura predicado-argumento não é de natureza hierárquica. 
C.: Então, a pergunta é: uma sintaxe assim, como é presente na fala? $\mathrm{Na}$ minha opinião, e naturalmente me refiro à minha Teoria da Língua em Ato, na fala, em primeiro lugar, há uma organização pragmática acional, em volta da qual se estruturam outros grupos de palavras, que também têm uma funcionalidade informacional, mas dominada por esse ponto central de caráter pragmático. Então, nesses grupos de palavras, encontra-se essa estruturação sintática. Mas se trata de uma sintaxe de tipo local, que vigora dentro da unidade de informação. Podemos também encontrar grupos de palavras que não realizam esse tipo de estruturação sintática. Então, frequentemente, podemos encontrar a estrutura do sintagma, mas é uma estruturação local. Quanto às relações entre grupos de palavras mais ou menos estruturadas sintagmaticamente nas diferentes unidades informacionais, não vigora mais uma estruturação de tipo hierárquico-recursiva. São sequências combinatórias desses grupos. Esse é, pra mim, o quadro da sintaxe da fala.

M.: Essa ideia era presente também no conceito de macrossintaxe de Claire BlancheBenveniste $^{5}$. A ideia de que a fala tem uma estruturação sintática feita por ilhas sintáticas. Os diferentes componentes, quer sejam unidades informacionais, quer sejam núcleos (como na teoria de Blanche-Benveniste) possuem uma estruturação interna rígida. Já as relações entre as estruturas informacionais (ou entre os núcleos) pertencem a um outro nível. Qual é esse outro nível, se se mantêm elementos de regência ou não, tudo isso pode variar muito do ponto de vista teórico. Contudo, a ideia de fundo, de que a sintaxe da fala seja organizada dentro de grupos mais autônomos, desenvolveu-se também com a teoria da macrossintaxe de BlancheBenveniste.

C.: Evidentemente o ponto de diferença forte com a teoria da macrossintaxe é que, para nós, a base da organização se fundamenta sobre um grupo pragmático voltado para a realização de uma ação, ou seja, em volta de uma ilocução.

\footnotetext{
${ }^{5}$ Importante linguista francesa. Veja-se, pelo menos, Le français parlé, Claire Blanche-Benveniste, CNRS, 1997; Eurom 4: méthode d'enseignement de quatre langues romanes, Claire Blanche-Benveniste, André Valli et alii, Firenze, Nuova Italia Éditrice, 1997; Constitution et exploitation d'un grand corpus, Claire Blanche-Benveniste, volume IV-1, p. 65-74, 1999.;
} 
M.: Recentemente, a esse respeito, o grupo Rhapsodie ${ }^{6}$ tem se aproximado muito da nossa visão.

C.: Sim. Eles também agora dão uma definição do núcleo do enunciado como ilocução. Contudo, depois definem a ilocução com base nas modalidades de frase e não enfrentam da mesma maneira que nós o conceito de ilocução. Mas, mesmo assim, talvez de maneira menos clara e definida, para todos aqueles que estudam a fala espontânea emerge essa característica, digamos assim, combinatória de grupos de palavras que constroem organizações sintáticas locais. Entre os grupos de palavras se delineiam hipóteses de relações textuais ou também de regência. Se propõem verbos que continuam a própria regência em turnos de falantes diferentes. Coisas que quem, como nós, tem uma posição fundamentada na ação, na ilocução, não pode aceitar, já que cada falante cumpre uma própria ação e as relações linguísticas se organizam em volta desse núcleo acional. De toda maneira, pra resumir, esse é o quadro da discussão sobre a sintaxe na fala. Na escrita, as coisas são diferentes.

E.: Certo, mas antes de falar da escrita, gostaria que falássemos um pouco da relação entre unidade tonal e sintaxe. E também sobre a relação que existe entre a sintaxe e a linearização, já que, na proposta de vocês, a fronteira prosódica, que delimita a unidade tonal, interrompe a linearização. Ou seja, considera-se linearizado somente o que está dentro do domínio prosódico da unidade tonal.

C.: Para mim, a fala, dada a sua natureza afetivo-pragmática, se organiza em volta de um núcleo que realiza o ato ilocutório. Mas, na unidade pragmático-afetiva (no enunciado), não há somente esse núcleo que cumpre a ilocução. Estar em relação com o outro significa fazer também outras coisas para que a ação comunicativa funcione. Por isso, às vezes, precisamos fornecer um escopo cognitivo para a ilocução, quando ele não é óbvio, e fazemos um tópico ; às vezes, precisamos de acrescentar uma informação no meio que sinalize algo de metalinguístico, e fazemos um parentético; às vezes, precisamos acrescentar algo sem uma função muito definida, mas que serve só para completar e integrar algo, então fazemos um apêndice; às vezes, as circunstâncias da interação tornam útil o uso de um alocutivo ou outra unidade dialógica, com

\footnotetext{
${ }^{6}$ Para os componentes do grupo e as bases teóricas, veja-se http://rhapsodie.ilpga.fr/wiki/Accueil
} 
a função de regular a comunicação etc. Enfim, o falante precisa fazer várias coisas, mas todas elas estão às voltas desse núcleo ilocutório acional, sem o qual não temos uma comunicação interpretável.

Toda essa organização centrada na ilocução e nas unidades informacionais opcionais em torno da ilocução é sinalizada prosodicamente. Portanto, a prosódia é a interface entre essa estrutura pragmático-informacional e os preenchimentos linguísticos, ou seja, semânticos e sintáticos, de cada grupo de palavras que serve para fazer o comentário, ou seja, a unidade ilocutória obrigatória, pra fazer um tópico, um parentético etc. Então, a prosódia é o que, digamos assim, empacota, embrulha o grupo de palavras que tem uma determinada função. E cada função tem um envelopamento diferente que sinaliza essa função pragmáticoinformacional.

Então, com relação ao conceito de unidade tonal, temos uma tendencial isomorfia entre a unidade prosódica de unidade tonal e a unidade pragmática de unidade informacional, ou seja, entre um padrão entonacional e um padrão informacional.

E.: Certo, mas a minha pergunta era um pouco diferente. Você diz que a sintaxe se realiza dentro da unidade informacional, ou seja, o escopo da sintaxe é a unidade informacional, que, como você acabou de dizer, é tendencialmente isomórfica com a unidade tonal. Então, qual é a relação entre a fronteira prosódica, que constitui a fronteira de unidade tonal, quase sempre também fronteira de unidade informacional, e essa capacidade de interromper a sintaxe? Qual a relação entre a fronteira que interrompe a linearidade e essa necessidade que a sintaxe tem de ser não somente hierárquica, mas também linear?

C.: Shlomo Iz'reel ${ }^{7}$ me dirige uma crítica muito certa. Ele me diz: "cuidado quando você chama de 'linear' algo que acontece na mesma unidade informacional, porque, no uso normal desse termo entende-se outra coisa". Usei a expressão "linear" para dizer que as palavras que são "linearizadas", ou seja, integradas (expressão talvez melhor) dentro um envelope prosódico (ou seja, dentro uma mesma unidade informacional) constituem uma estrutura linear unitária.

\footnotetext{
${ }^{7}$ Importante linguista israelense, especialista de línguas do Oriente Médio e estudioso da fala.
} 
E.: Mas eu queria colocar uma outra questão, ou seja, dizer que para que exista uma hierarquia sintática é preciso que exista uma linearidade. Nós falamos em hierarquia na sintaxe, mas a hierarquia é o que não aparece; o que aparece é a linearidade. A hierarquia é uma característica mental possível somente porque existe a linearidade. Então, nesse sentido, a fronteira prosódica interrompe a linearidade e, portanto, interrompe também a hierarquia. Ou seja, a hierarquia é consequência da linearidade, e, se através da prosódia nós sinalizamos que não há mais linearidade, é normal que seja interrompida também a hierarquia.

M.: Do ponto de vista formal, nós podemos ter duas sequências lineares interrompidas por um parentético; nesse caso, a segunda sequência linear recupera as relações sintáticas com a primeira.

E.: Sim, e, de fato, isso é admissível na teoria, porque se trata de uma interrupção de uma mesma unidade informacional, ou seja, não se interrompe a sequência sintática que se constrói ao longo da unidade informacional.

M.: É claro, mas é muito relevante que o parentético possa interromper uma outra unidade somente depois de uma pré-tônica, ou seja, o elemento prosódico que sinaliza a função informacional da unidade deve ser necessariamente colocado depois da interrupção. Isso significa que as restrições prosódicas para a não interrompibilidade da sequência linear e hierárquica devem ser consideradas. O núcleo prosódico da unidade interrompida pelo parentético deve, necessariamente, estar depois da interrupção. Essa é uma restrição importante para uma premissa, aquela da interrompibilidade da unidade informacional, que já é extremamente periférica na teoria.

E.: Enfim, a objeção do Iz'reel não é uma verdadeira objeção; no caso, seria mais um pedido para explicar melhor a relação entre o conceito de linearidade e como a quebra prosódica interfere nesse conceito.

C.: Sim. De fato, esse é um ponto de contraste com os franceses, tanto os seguidores da BlancheBenveniste e da teoria da macrossintaxe, quanto os membros do grupo Raphsodie, que falam de núcleo de relações sintáticas locais, mas depois acabam sempre readmitindo a dominância 
das relações sintáticas sem considerar a função das fronteiras prosódicas. O que eles fazem é estudar a prosódia e a sintaxe de maneira independente e paralela, e depois comparam os resultados de um caminho com os resultados do outro, sem uma abordagem que integra os dois componentes em uma visão unitária desde o começo.

A questão chave é exatamente essa: como integrar prosódia e sintaxe. Posso dar agora um exemplo que dou no artigo que será publicado no livro que vocês estão editando ${ }^{8}$. Estudando as completivas, emerge que existem essas estruturas completivas nas quais o sujeito da completiva está no tópico e somente o predicado está no comentário. Uma estrutura do tipo: eu acho que Maria / vem amanhã //. Nessa estrutura “eu acho que Maria” é uma unidade de tópico, com a típica prosódia do tópico, separada pela fronteira prosódica da unidade de comentário "vem amanhã" que, como qualquer ilocução, é interpretável em isolamento. Essa estrutura parece ser aquela mais frequente em corpus de fala espontânea entre as estruturas completivas com expressão do sujeito da completiva. Isso é claramente um conflito do que seria uma escansão regular da sentença. O conflito, note-se bem, é com uma estrutura de sentença, não com uma estrutura de sintagma. É difícil, por exemplo, separar o verbo do objeto com uma fronteira prosódica.

E.: Pode acontecer com o unidades de apêndice.

M.: Eu diria que acontece pouco e acontece mal. Esse é um ponto que já discutimos há muito tempo, sobre a relação entre a unidade de apêndice e o comentário. Notamos que a possibilidade de colocar os objetơs em apêndice é específica daqueles verbos que possuem uma interpretação absoluta. Enquanto é muito duvidosa essa interpretação com os verbos que precisam de um objeto. Por exemplo, Mario come a sopa e Mario abre a porta têm a mesma estrutura; mas eu posso dizer Mário come / a sopa // (com prosódia de apêndice, ou seja, uma prosódia na segunda unidade com uma frequência fundamental mais baixa e cujo movimento é nivelado ou descendente). No entanto não posso pronunciar Mário abre / a porta // com essa mesma prosódia. Então, essa impossibilidade de separar o objeto do verbo confirma a premissa. No primeiro caso, "a sopa" não faz parte do mesmo sintagma de come, que é interpretável com

\footnotetext{
${ }^{8}$ Cresti se refere ao trabalho que está no prelo em Spoken Corpora and Linguistic Studies (T. Raso and H. Mello
} Eds.). Amsterdam: John Benjamins. 
valor absoluto. Em italiano, eu posso dizer Mario la apre / la porta //. Isso porque o clítico preenche o argumento necessário do verbo dentro da mesma unidade tonal, e depois o apêndice hospeda a simples retomada, que explicita lexicalmente o objeto, mas não ocupa a posição argumental.

C.: O apêndice não é uma unidade informacional frequente e, portanto, não temos uma grande quantidade de casos em corpus sobre os quais analisar as suas possibilidades sintáticas. Em apêndice, normalmente achamos correções, precisações, integrações, e não um elemento argumental. Por exemplo, algo como ele abriu a garagem / o portão // ou ele abriu a porta / de casa //. Enfim, parece-me que o apêndice não cria problemas para a estrutura. Mas precisaríamos ter mais dados para uma análise mais definitiva dessa questão.

E.: Então vamos passar para a escrita, como você já queria fazer antes.

C.: Certo. Se olhamos para a escrita como uma modalidade de expressão e de formalização diferente da fala, ou seja, que não se apresenta como uma manifestação afetivo-corporal como a fala, mas uma modalidade diferente disso, podemos fazer várias considerações.

A humanidade, a um certo ponto, encontrou a possibilidade de representação do pensamento através da linha, uma outra capacidade própria da espécie sapiens. Mas se trata de algo que não possui o aspecto corporal que é próprio da fala. Produz uma codificação do pensamento que leva à produção de grandes obras literárias, legislativas etc. Algo de muito diferentes dos produtos da fala. Portanto, essa modalidade escrita precisa criar instrumentos que permitam uma complexidade na dimensão da linguagem escrita. A linguagem escrita que se codifica de maneira potente através da linha precisa da sintaxe. A sintaxe existe também na fala, mas de maneira reduzida, porque, por trás da fala existe uma acionalidade, e porque existe a prosódia, que marca tanto a acionalidade como as outras ilhas informacionais não acionais.

Na escrita, não temos prosódia e não temos acionalidade, mas temos essa possibilidade, esse interesse, esse esforço de fazer representações amplas, fortemente estruturadas de elaborações que têm um valor além do contingente. As possibilidades da sintaxe são, portanto, levadas às suas consequências mais complexas, de modo que os objetivos da modalidade escrita (não acional e sem os recursos da prosódia) possam se expressar. Nessa mesma direção, vai a pontuação, a necessidade de uma codificação mais geral através de tecnologias como a 
imprensa ou os meios de comunicação de massa. Tudo isso leva a uma progressiva especialização, a um refinamento, a uma complexificação da sintaxe. A própria sintaxe é desenvolvida, é codificada através da escrita.

E.: Os próprios textos antigos são muito pobres do ponto de vista sintático.

C.: Eu sei pouco disso, mas sei que a codificação das gramáticas das línguas nacionais modernas é fortemente ligada à imprensa, à produção de textos coletivos. Sabemos, por exemplo, que a parataxe na língua moderna é um estilo específico de certos escritores. A parataxe, por exemplo, é muito presente nos títulos dos jornais, mas são usos especializados. $\mathrm{O}$ corpo do texto não se estrutura de maneira paratática. A parataxe na escrita fica para realizar um efeito estilístico expressivo de certas tipologias específicas. É um uso reflexo, não mais natural. Nas línguas antigas, temos a famosa para-hipotaxe. Mas não se trata de parataxe e hipotaxe juntas, é uma outra coisa. As gramáticas não entendem esse ponto.

E.: Sim, se limitam a fazer a analogia com o que se conhece, ao invés de analisar uma coisa diferente pelo que ela é: algo diferente mesmo.

C.: Exatamente. Enfim, a sintaxe na escrita leva a uma proliferação de estruturas e possibilidades que raramente são realizadas na fala.

M.: Eu acho que um ponto fundamental é o conceito de proposição. A escrita sem, proposição, não existe. Não que na fala não exista a proposição, mas é pouco relevante. Esse aspecto me parece ir além do discurso do sintagma.

C.: Esse é um ponto muito importante. É a escrita que leva à sentença, composta de dois sintagmas, um de valor verbal ou predicativo e outro de valor não predicativo, com a correspondente entidade semântica de valor verdadeiro condicional. Por que a lógica se fundamenta na proposição? Porque parte do estudo da linguagem escrita. E Massimo dizia antes que um interesse da lógica é estudar o sentido das conjunções, o valor de verdade das subordinadas. São coisas ligadas às características da escrita. 
E.: É possível dizer que a escrita induz à "linearização", usando esse termo em duas acepções, ao mesmo tempo para coligar a ideia da linha, como origem da escrita, e a necessidade de uma estruturação de tipo fortemente sintático?

C.: Sim, acho que sim, mantendo a noção de que linha, aqui, refere-se a duas coisas diferentes, mas ambas próprias da escrita. Na fala, nós temos uma "linearização" no tempo; na escrita, através do uso da linha, temos uma linearização no espaço.

E.: Mas a linearização na fala é uma linearização que pode ser interrompida. E essa interrupção é sinalizada pela prosódia. Na escrita, a linearização não pode ser interrompida. Ou melhor, é interrompida pela pontuação. E isso me leva ao ultimo passo que eu gostaria de dar nessa entrevista. Qual a relação e a diferença entre prosódia e pontuação?

C.: É uma diferença fundamental. Em primeiro lugar, por muitíssimo tempo, tivemos uma escrita "contínua", sem pontuação e sem separação entre uma palavra e outra, o que gera muitos problemas na interpretação dos textos. A pontuação é algo muito recente e muito diferente de uma tradição a outra.

M.: A pontuação é fortemente convencional. Hoje, por exemplo, quem não governa bem o registro escrito tende a colocar uma vírgula entre o sujeito e o verbo, onde, na fala, colocaria uma fronteira prosódica se quisesse fazer um tópico, e o professor marca isso como erro grave. Isso porque a pontuação não obedece às regras da prosódia, pelo simples fato de que a organização da esçita é diferente da organização da fala.

C.: Na literatura, os artistas fazem uma pesquisa complexa de tipo estilístico sobre o uso dos sinais de pontuação. Pensemos em Saramago e seus experimentos.

M.: Contini $^{9}$ era conhecido por corrigir a pontuação de Gadda $^{10}$, que naturalmente o olhava como se fosse doido. Isso nos diz também uma outra coisa, ou seja, que a escrita é também

\footnotetext{
${ }^{9}$ Grande filólogo e crítico literário italiano.

${ }^{10}$ Importante autor italiano (1893-1973).
} 
muito ligada à invenção literária. Trata-se de um jogo aberto, de natureza criativa, que é próprio da escrita, muito mais do que na oralidade.

E.: E, com isso, voltamos também à origem criativa da escrita graças aos desenhos das cavernas.

M.: Carmelo Bene ${ }^{11}$ dizia "transpor a escrita no descolorido oral".

${ }^{11}$ Ator, dramaturgo e cineasta italiano. 